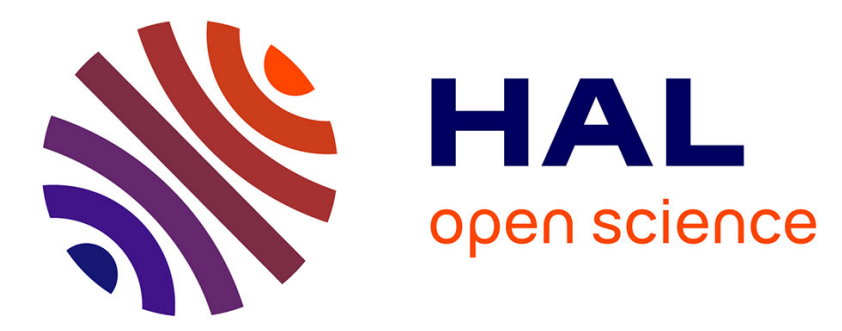

\title{
Analysis of multiple fatigue cracks-part II: Results
} Marie-Christine Baietto, Murielle Godet, B. Villechaise

\section{To cite this version:}

Marie-Christine Baietto, Murielle Godet, B. Villechaise. Analysis of multiple fatigue cracks-part II: Results. Journal of Tribology, 1992, 114 (3), pp.462-468. 10.1115/1.2920906 . hal-01951918

\section{HAL Id: hal-01951918 https://hal.science/hal-01951918}

Submitted on 7 Jul 2021

HAL is a multi-disciplinary open access archive for the deposit and dissemination of scientific research documents, whether they are published or not. The documents may come from teaching and research institutions in France or abroad, or from public or private research centers
L'archive ouverte pluridisciplinaire HAL, est destinée au dépôt et à la diffusion de documents scientifiques de niveau recherche, publiés ou non, émanant des établissements d'enseignement et de recherche français ou étrangers, des laboratoires publics ou privés. 


\section{Analysis of Multiple Fatigue Cracks-Part II: Results}

\begin{abstract}
A semianalytical model of multiple fatigue crack analysis in sliding contact is developed. Linear elastic fracture mechanics is applied. Frictional resistance between crack faces is taken into account. Five crack interaction mechanisms have been identified. Load transfer between cracks can cause both significant increases and drops in stress intensity factors both in mode I and II. The interaction depends on the distance between cracks, their relative position with respect to the loading zone, and the interfacial crack coefficient of friction.
\end{abstract}

M. C. Dubourg

M. Godet

\author{
Laboratoire de Mécanique des Contacts \\ (CNRS URA 856) \\ Institut National des Sciences Appliquées \\ de Lyon, \\ 69621 Villeurbanne Cédex, France
}

B. Villechaise

Laboratoire de Mécanique des Solides (CNRS URA 861),

Université de Poitiers,

86022 Poitiers Cédex, France

\section{Introduction}

Evidence of multiple fatigue cracks is common in fatigue test specimens (Endo, 1981), (Zhou et al., 1990, Fig. 1) and in engineering applications (Forsyth, 1981, Broek, 1989, Berthe et al, 1980) where fretting (cables, quasi-static links...), rolling contact fatigue (gears, cams, ball and roller bearings..) are encountered. It is therefore necessary to understand how load is transferred between these cracks and to calculate the modified stress intensity factors (SIF) $K_{1 j k}$ and $K_{2 j k}(j, k=1,2)$. A parametric study of interactions between two cracks situated close to a sliding contact is undertaken here. Pure mode II and mixed mode (I + II) loading conditions are considered. The purpose is threefold: to understand interaction phenomena, to quantify the interaction level and to identify the interaction domain.

The model used in this study is presented in the first part of this paper (Dubourg, Villechaise, 1991). It is a semianalytical dislocation model for elastic fields with multiple cracks situated close to the loading zone. Cracks are analyzed simultaneously. Coulomb friction between crack faces is included in the model. No assumptions concerning the boundary conditions between the crack faces (i.e., the stick-slip-open configurations) are needed in this analysis as this contact problem is solved as a unilateral frictional contact problem according to the technique developed by Kalker for two body rolling contact (Kalker, 1990). Therefore multiple cracks in any number, length, angle, coefficient of friction, submitted to any type of loading, can be modeled; further, complete load cycles can be analyzed.

\section{Model}

A Hertzian traction distribution with normal $(p(y))$ and tangential $(q(y))$ components is applied to an elastic halfplane with multiple cracks (Fig. 2). Stress and displacements fields $\left(\sigma^{T}, \delta u, \delta v\right)$ are given by superposing the uncracked halfplane $\left(\sigma^{M C}\right)$ and the crack response $\left(\sigma^{F}, \delta u, \delta v\right)$ to the load, in such a way that $\sigma^{T}$ satisfies the boundary conditions along the faces of the presumed cracks. Here $\delta u$ and $\delta v$ are the relative displacements along the crack faces. Relative displacement zones are modeled as continuous distributions of edge dislocations $b x$ and $b y$. In the pioneering work of Comninou (1978) and others (Hills and Comninou, 1985a, b) the dislocation behavior on each displacement zone is dictated by the stress behavior-regular or square root singular - and several a priori assumptions regarding the contact area division have to be made. This limitation is removed in the model presented here. A single formulation for the crack fields, applicable to the whole crack is developed. It is independent of the final contact division on the crack and depends only on the crack geometry (subsurface or surface breaking). Correct behavior of the stress field along the crack is respected. Further, this formulation, connected with the contact problem solution as a unilateral contact problem with friction, gives automatically the contact configuration along the crack faces.

This method was presented in detail previously for single (Dubourg and Villechaise, 1989) and multiple crack (Dubourg, 1989) configurations. Comparisons were performed with published papers for the single crack configuration (Hills and Comninou, 1985a,b; Dubourg, 1989).

\section{Interaction Between Cracks}

Different interaction mechanisms occur between cracks; they depend on the distance between cracks, the relative position with respect to the loading zone, the interfacial crack coefficient of friction, and the loading mode conditions (mode II or mixed mode I + II). These mechanisms are first described, then quantified, and finally, illustrated by a few examples. For simplicity, this analysis considers only two cracks, labeled 1 and 2, perpendicular to the surface. As cracks are generally found near the edges (Fig. 1) of the loaded areas where large tensile stresses exist (Endo, 1981, Smith and Liu, 1953; Chivers and Gordelier, 1985), crack 1 is placed at the origin $y=d y$ 


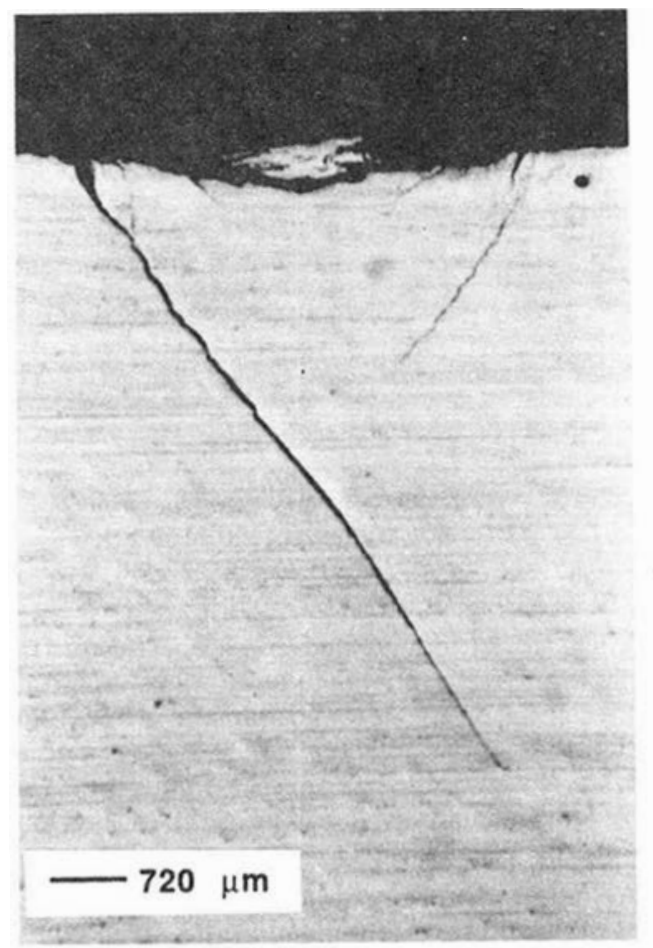

Fig. 1 Fretting fatigue cracks in aluminium alloy (2091T851) after $10^{6}$ cycles normal load $1000 \mathrm{~N}$, amplitude displacement $\pm 35 \mu \mathrm{m}$, frequency $=5 \mathrm{~Hz}$ )

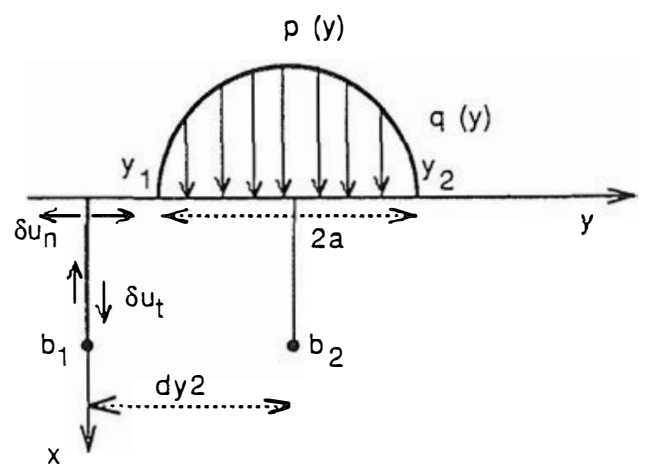

Fig. 2 Configuration studied

$1=0$, i.e., just to the left of the loaded zone. Crack 2 can sweep across the half plane $-4 a<d y 2<4 a$ (Fig. 2).

III.1 Crack Interaction Phenomena. Five interaction mechanisms, among those identified for the two crack configurations studied, are shown schematically in Fig. 3. Displacements are grossly magnified and the "continuum" elastic deformations are ignored to emphasize the displacements along cracks. Step and tilt effects are noted when both cracks are

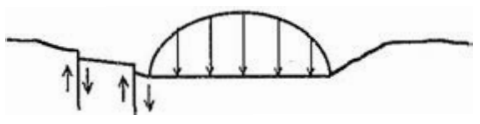

Fig. 3(a) Step effect

Fig. 3(b) Positive tilt effect

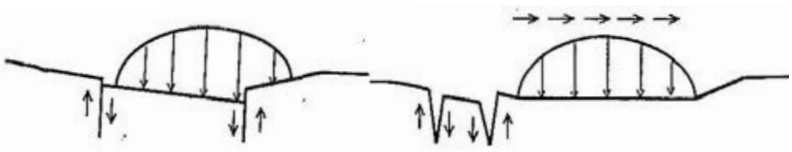

Fig. 3(c) Negative tilt effect

Fig. 3(d) Stretch effect
Fig. 3(e) Plug effect

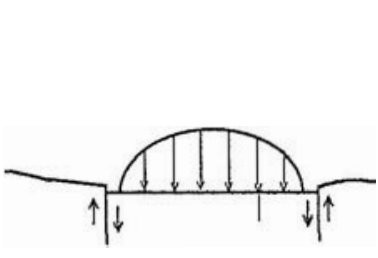

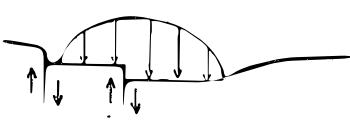

\section{Fig. $3(0)$ Stretch eflect}

Fig. 3(e) Plug eftect

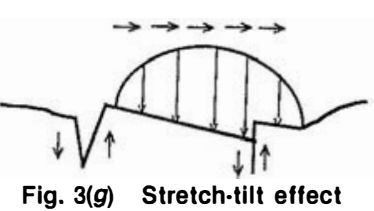

Fig. 3 Different interaction mechanisms loaded in mode II, stretch effect is found under mixed mode loading conditions. These are basic mechanisms that govern crack interactions. All combinations of these different mechanisms are, of course, possible. In the specific case of the two crack configuration, we will discuss two further combinations the stretch-tilt and the plug effects.

The step effect (Fig. 3(a)): The load is sheared between both cracks, each crack thus unloads the other.

The tilt effect (Fig. 3(b) and 3(c)): Its effect on cracks depends on the position of the tilting pivot which is governed by the load distribution over the contact area concerned by the tilt. Both cracks are unloaded (Fig. $3(b)$ ) as shear along crack 2 reduces slip along crack 1 and vice versa, or overloaded (Fig. $3(c)$ ) as shear along crack 2 favors slip along crack 1 and vice versa.

The stretch effect (Fig. 3(d)): Both cracks are open; slab stiffness, which varies with depth, redistributes the load between cracks which are thus individually less loaded.

The plug effect (Fig. 3(e)): (a double step) The section of the slab between the two cracks is pushed down as a plug. Both cracks are overloaded.

The stretch-tilt effect (Fig, $3(f)$ and $3(g)$ ): One crack is open, the other is partially or fully closed. Two conditions are met depending on crack position relative to the loaded zone.

$$
\begin{aligned}
& \text { Nomenclature } \\
& p(y), q(y)=\text { distributed normal } \\
& a=\text { half width of the } \\
& \text { loading zone } \\
& \mu=\text { tangential to normal } \\
& \text { load ratio } \\
& K_{i j k}=\text { SIF in mode } i \text { for } \\
& K_{i \text { ref } j}=\text { SIF in mode } i \text { for }
\end{aligned}
$$


If crack 2 is located to the left of crack 1 , (Fig. $3(f)$ ), shear along crack 1 reduces crack 2 opening and vice versa. The load is shared and both cracks are individually unloaded. If crack 1 is open and crack 2 closed (Fig. $3(g)$ ) the crack 2 eases crack 1 opening and vice versa. The stretch-tilt effect is governed by interfacial slip amplitude and thus by crack coefficient of friction.

III.2 Crack Interaction Level and Domain. Three parameters, the reference SIF $K_{\text {ref }}$, the interaction factor IF, and the interaction domain ID characterize the interaction between the two cracks of Fig. 1.

$K_{1 \text { ref } 1}$ and $K_{2 \text { ref } 1}$ are the values of the SIF1 and SIF2 calculated for crack 1 in the absence of crack 2 . As the abscissa of crack 1 is fixed $K_{1 \text { ref1 }}$ and $K_{2 \text { ref } 1}$ are only defined at one point. $K_{1 \text { ref2 }}$ and $K_{2 \text { ref2 }}$ are the values of the SIFs calculated for crack 2 alone. As the abscissa $d y 2$ of crack 2 varies, these values depend on $d y 2$.

IF is given by the relation:

$$
\mathrm{IF}=\left(|K|-\left|K_{\text {ref }}\right|\right) /\left|K_{\text {ref }}\right|
$$

where $K$ is the value of the SIF which corresponds to $K_{\text {ref }}$ calculated when both cracks are present, all other parameters being equal. IF indicates the percentage change in $K_{\text {ref }}$ brought about by the presence of the other crack. As such four values of IF, denoted $\mathrm{IF}_{a b c}$ can be defined, where " $\mathrm{a}$ " denotes the SIF mode ( 1 or 2$)$ and "bc" states that it is the effect of crack c on crack b, and thus on $K_{a \text { ref } b}$. Thus $\mathrm{IF}_{212}$ characterizes the effect of crack 2 on the reference SIF mode 2 of crack 1 . A positive IF characterizes an increase in SIF and vice versa. A similar code will be used to label the SIFs. $K_{a b c}$ refers to the SIFa of crack $b$ in presence of crack c; thus $K_{212}$ is the SIF2 of crack 1 when crack 2 is present. All terms are defined in the nomenclature. Plots of either $\mathrm{IF}_{a b c}$ and $K_{a b c}$ will be given below.

ID specifies the limits $y_{m}$ and $y_{n}$ of the interaction domain in which the corresponding IF is different from zero or less than a given percentage. Thus $\operatorname{ID}_{221}\left[y_{m}, y_{n}\right]$ states that the presence of crack 1 modifies the SIF mode 2 of crack 2 for $y_{m}<y<y_{n}$.

The interaction mechanisms between two cracks perpendicular to the surface were illustrated and the parameters required to quantify these interactions identified. Examples taken from an extensive parametric study are now given below.

\section{Examples}

Crack interaction versus crack distance $d$, crack lengths $b 1$ and $b 2$, crack coefficients of friction $f 1$ and $f 2$ and loading conditions was analyzed.

\section{IV.1 Material Properties and Boundary Conditions:}

(a) Half-plane properties:

Young's modulus $\mathrm{E}=210000 \mathrm{MPa}$

Poisson's ratio $\quad \nu=0.3$

Yield stress $\quad \sigma_{o}=1800 \mathrm{MPa}$

Tensile strength $\quad \sigma_{y}=2010 \mathrm{MPa}$

Toughness $\quad \mathrm{K}_{\mathrm{IC}}=76 \mathrm{MPa} \sqrt{\mathrm{m}}$

Threshold value $\Delta K_{\mathrm{th}}=2.7 \mathrm{MPa} \sqrt{\mathrm{m}}$ for $\mathrm{R}=\sigma \mathrm{min} /$ $\sigma \max =0.67$

These values correspond to those of high strength steels commonly used in aerospace applications.

(b) Boundary conditions: normal load: $0.15 \mathrm{MN} / \mathrm{m}$ maximal hertzian pressure: $600 \mathrm{MPa}$ Load area $2 a=[y 1, y 2]=[10 \mu \mathrm{m}, 330 \mu \mathrm{m}]=320 \mu \mathrm{m}$

Traction is related to the normal pressure by Coulomb's law $(q o=\mu p o)$. Different values of $\mu$ are considered: $0 ., 0.3,0.5$, $0.7,1$. The rest of the surface is load free.

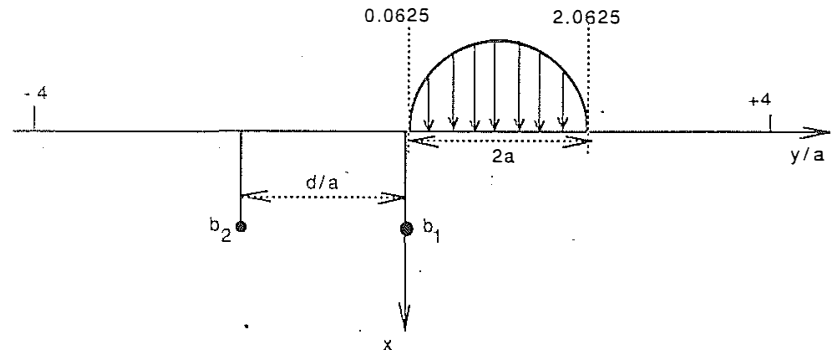

Fig. 4 Crack 2 possible location $d / a$ varying from $d / a=-4$ to $d / a=4$.

(c) Crack parameters:

$b 1=b 2=80,100,120,140,160 \mu \mathrm{m}$

$-2.5<d / a<3$ or $-4<d / a<4$

$f 1=f 2=0 ., 0.1,0.3,0.5,0.7$.

Crack lengths $b 1$ and $b 2$ and crack coefficients of friction $f 1$ and $f 2$ are respectively taken as equal in this study. Crack 1 is situated at the reference axis origin and is thus $10 \mu \mathrm{m}$ behind the trailing edge of the indenter. Crack 2 spans a domain (Fig. 4) which starts well to the left of crack 1 and of the load region $(d / a=-4)$ and ends well to the right of the load region $(d / a=4)$.

(d) Assumptions:

Steady-state and plain strain conditions are assumed. Linear elastic fracture mechanics (LEFM) conditions are considered which require that the dimensions of the plastic zone around the crack tip are less than 5 to 20 percent of the crack length (Chaboche, 1985).

(e) Verification:

The last assumption is checked by computing the dimensions of the yield zone determined for a multiple crack configuration according to the Tresca criterion and for $\mu=1 ., f=0.1$, $b=80 \mu \mathrm{m}, d y 2=150 \mu \mathrm{m} . d y 2$ is chosen to maximize the yield zone: for this location increase in $\mathrm{K} 1$ for crack 1 due to the presence of crack 2 is maximum. $\sigma \max / \sigma o$ contours are drawn in Fig. 5 which shows that the largest $\sigma \max / \sigma$ o contour is less than 1, the LEFM assumptions are therefore satisfied.

IV. 2 Mode II Loading Conditions: $\boldsymbol{\mu}=\mathbf{0}$. Figure 6 shows that crack distance $d$ and crack position with respect to the loading zone govern crack interaction. Variation of $K_{2 \text { ref1 }}, K_{2 \text { ref2 }}$, $K_{221}, K_{212}$ versus crack 2 abscissa $d / a=d y 2 / a$ are plotted for a pure normal load, $140 \mu \mathrm{m}$ long frictionless cracks $(\mu=0$, $f=0, b 1=b 2=140 \mu \mathrm{m}) . K_{221}$ and $K_{212}$ variations are not presented around $d / a=0$ due to their singular behavior. Interaction phenomena are thus clearly visible. Four zones are indentified versus abscissa $d / a$.

Zone 1. $d / a<-0.4375$ : Tilt effect: Crack 1 overloads crack 2. $K_{221}$ is proportionately much larger than $K_{2 \text { ref } 2}$; the corresponding $\mathrm{IF}_{221}$ reaches 200 percent but absolute values are small. The increase is thus of limited consequence.

Zone 2. $-0.4375<-d / a<0.5625$ : Step effect: both cracks are unloaded, $K_{212}$ and $K_{221}$ are both lower by up to 30 percent than their references $K_{2 \text { ref1 }}$ and $K_{2 \text { ref2 }}$. As crack 2 nears crack 1 , the step effect replaced the tilt effect. Note that zone 2 is centered on the left edge of the loaded zone $y 1=10 \mu \mathrm{m}$ or $y 1 / a=0.0625$, and that its width is a.

Zone 3. $0.5625<d / a<1.0625$ : Tilt effect: (In fact it is a combination of tilt and plug effects in which the tilt effect is dominant.) Crack 1 and 2 are respectively slightly overloaded and unloaded. As crack 2 advances under the loaded region, the slab on both sides of the crack deflects and the interfacial crack sliding is reduced ( $K_{2 \text { ref2 }}$ drops). As a consequence, The tilt effect drops and becomes nil when crack 2 is situated in the middle of the loading zone for $d / a=1.0625$.

Zone 4: $1.0625<d / a<2$ : Plug effect: (Again a combi- 


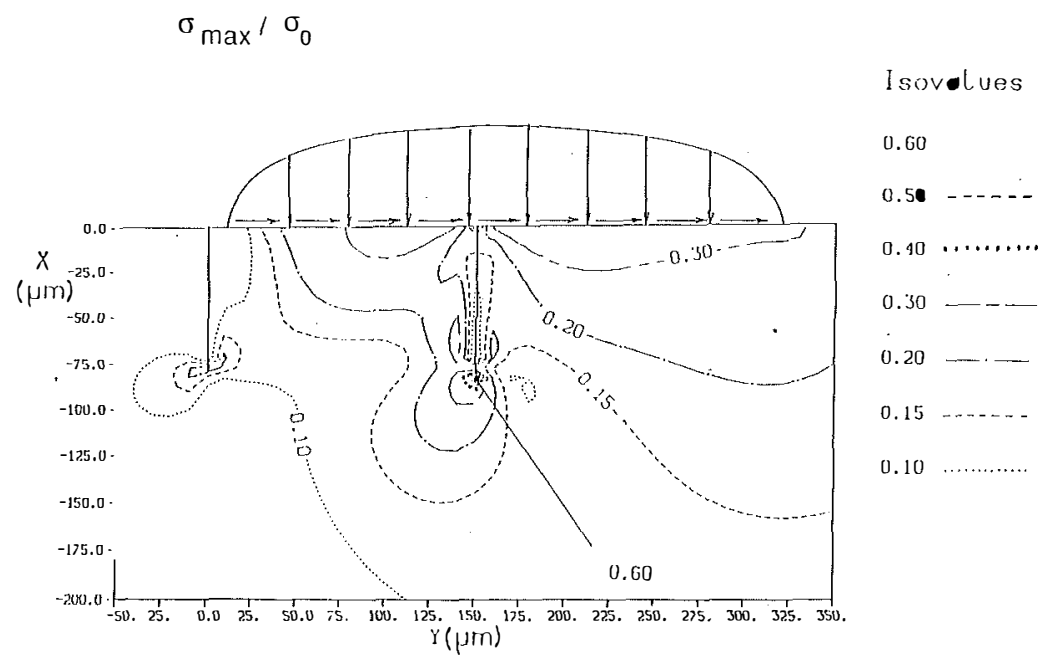

Fig. 5 Tmax $/ \delta$ o contours. $\mu=1, b=80 \mu \mathrm{m}, d=150 \mu \mathrm{m}, f=0.1$. Mesh dimensions $x=10 \mu \mathrm{m}, y=5 \mu \mathrm{m}$.

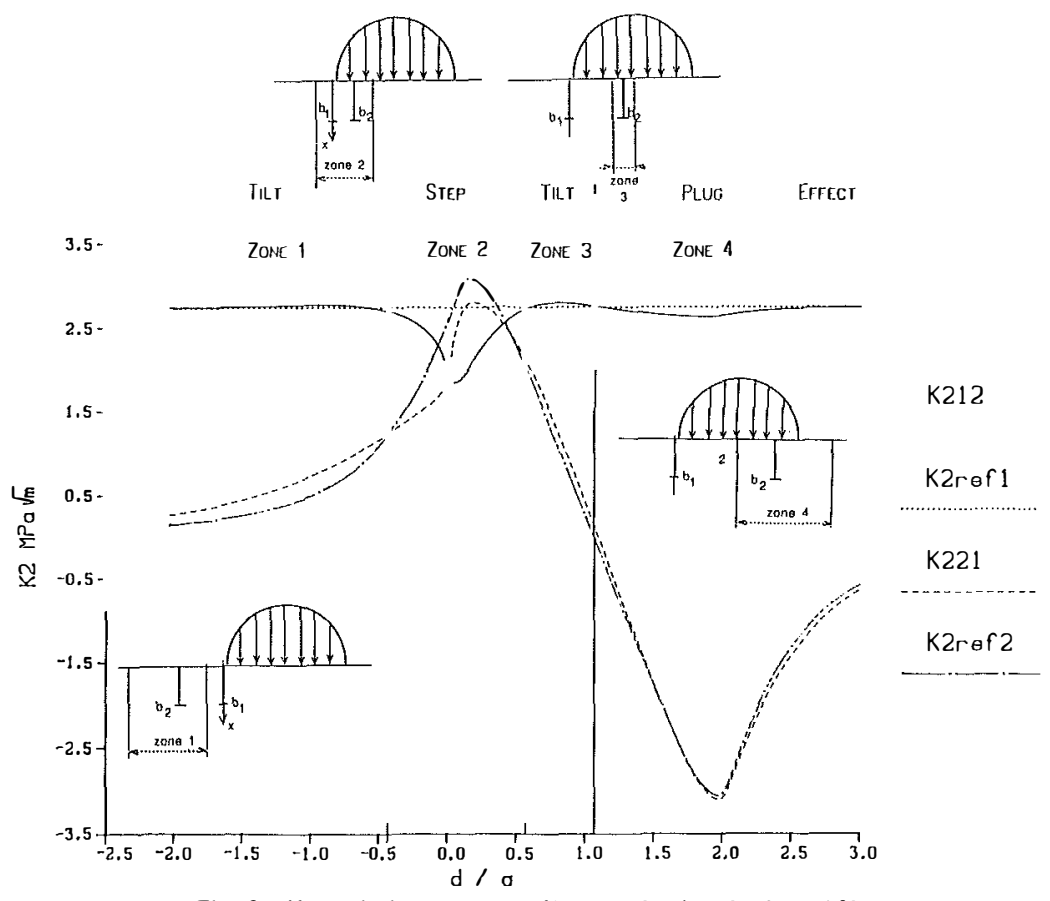

Fig. 6 K2 variations versus $d / a . \mu=0 ., f=0 ., b=140 \mu \mathrm{m}$.

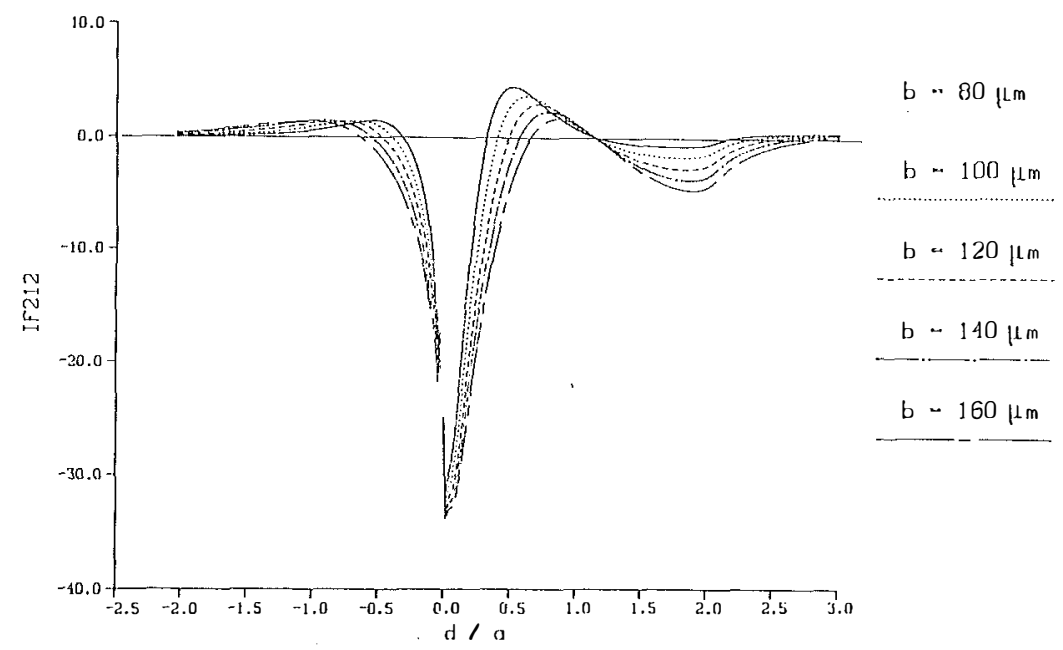

Fig. $7 \quad I_{212}$ variations versus $d / a$ for different crack lengths. $\mu=0$,

$f=0$. 


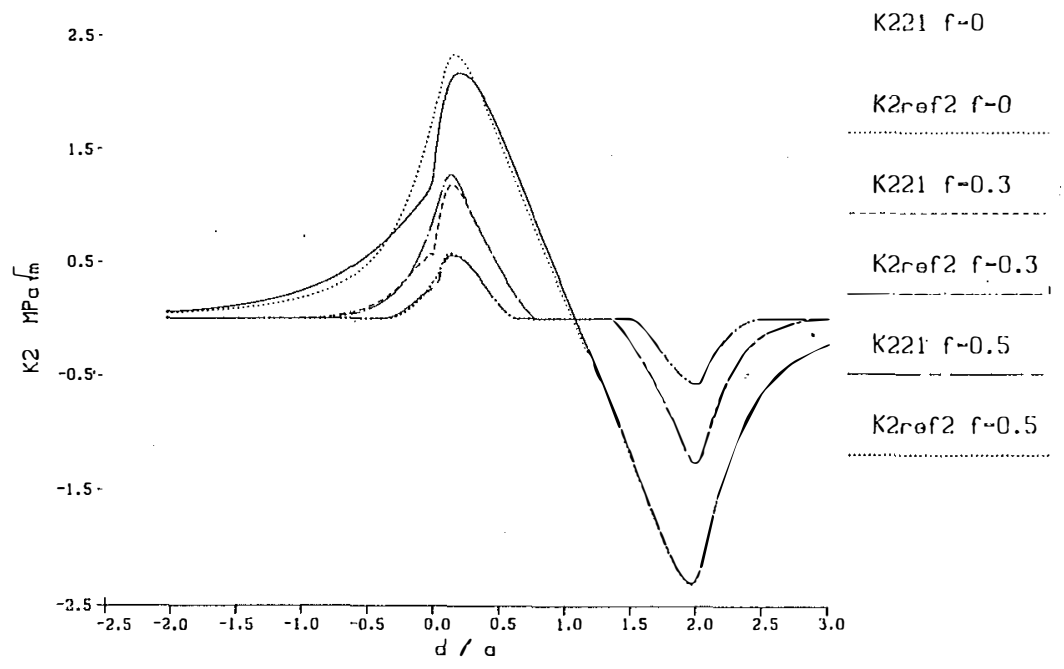

Fig. $8 \quad K_{221}$ and $K_{2 \text { ref } 2}$ variations versus $d / a$. Effect of interfacial friction. $\mu=0, b=80 \mu \mathrm{m}$.

$10.0-$

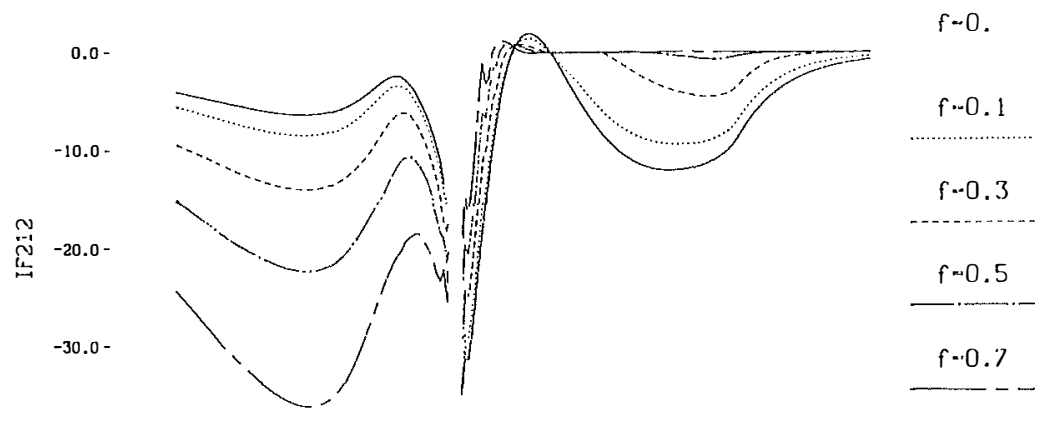

$-10.0-$

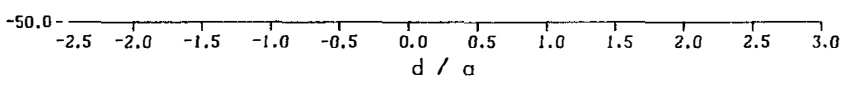

Fig. $9(a) \quad I F_{212}=g(d / a)$

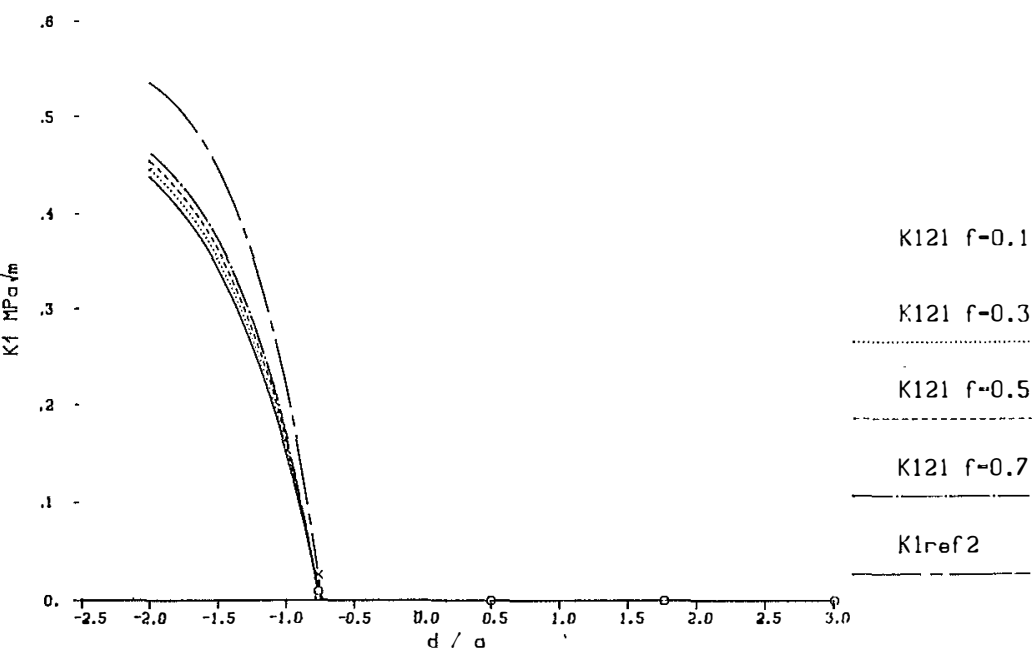

Fig. $9(b) \quad K_{121}$ and $K_{1 \text { ret2 }}=h(d / a)$

Fig. 9 Effect of tangential load on crack interactions for various coef ficient of friction. $\mu=0.3, b=140 \mu \mathrm{m}$.

nation of tilt and plug effects, but here it is the plug effect which is preponderant.) Crack 1 is slightly unloaded. As the direction of crack 2 interfacial sliding is inverted, the plug effect replaces the tilt effect.
The plug-tilt effect was not isolated because in the cases studied one of the mechanisms plug or tilt was dominant.

These trends are the same for all crack lengths $b 1=b 2$. Note that both IF and ID increase with increasing crack length 


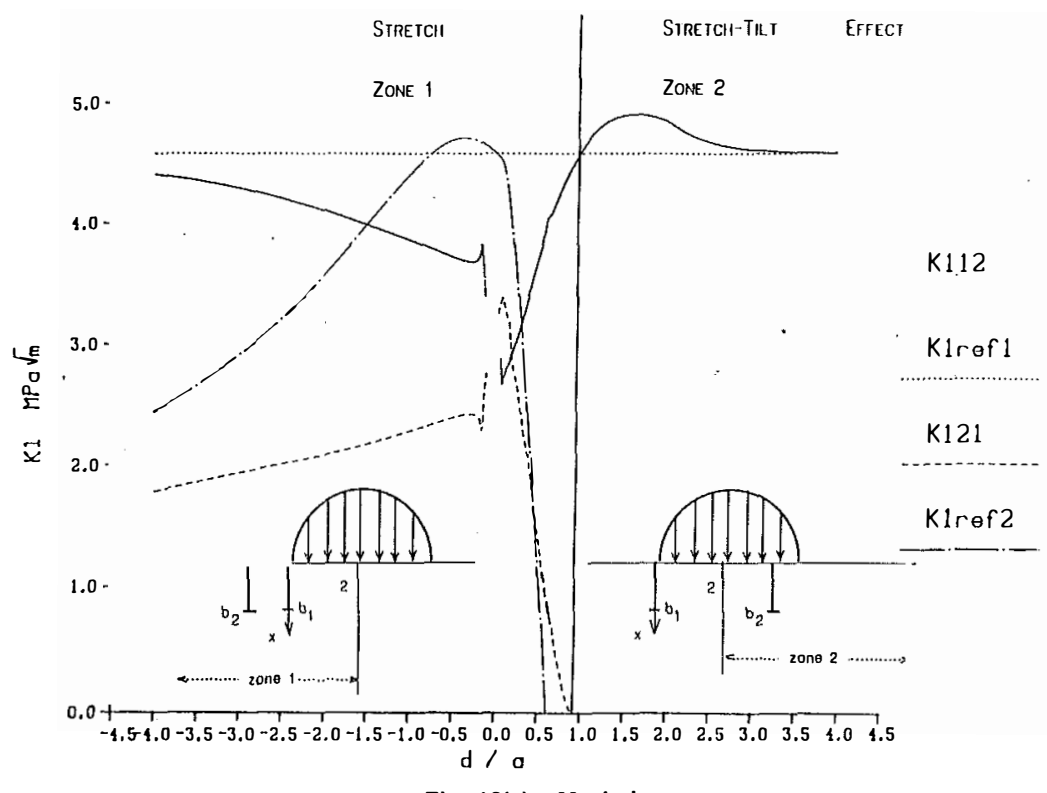

Fig. 10(a) Mode I

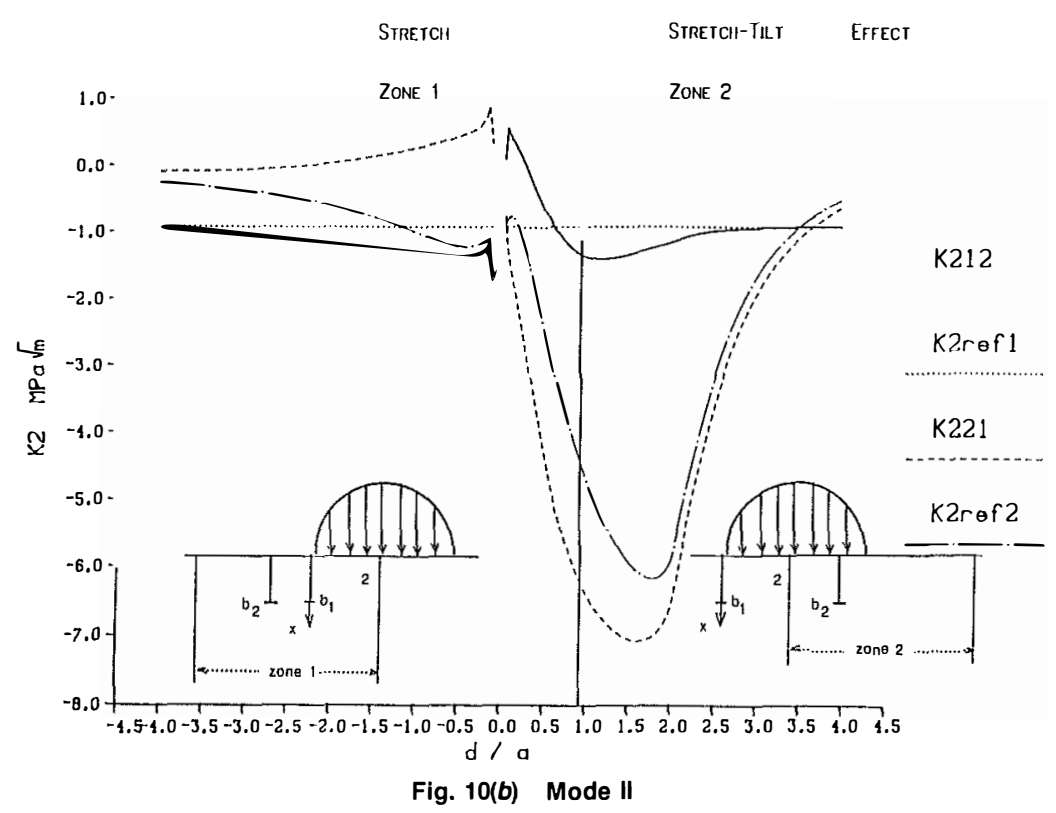

Fig. 10 Elfect of tangential load on crack interactions when crack 1 is completely open. $\mu=1, f=0.1, b=140 \mu \mathrm{m}$.

(Fig. 7). More precisely, ID is of the order of magnitude of crack length and increases linearly with crack length (ID = $0.645 a$ for $b=80 \mu \mathrm{m}$ and ID $=1.29 a$ for $b=160 \mu \mathrm{m})$.

Interaction mechanisms are limited to the step effect (zone 2) with increasing friction: Crack 2 is fully adherent on a zone which increases with increasing friction (Fig. 8) and as the tilt (zone 3 ) and the plug (zone 4) effects are indeed dependant on relative slip between crack 2 faces, they disappear. Further, zone 2 contracts with increasing friction as well as IF.

\section{Conclusion}

The interaction domain is limited to zone 2 for both cracks. Interactions on zone 1 for crack 2 are related to small values of $K_{2 \text { ref2 }}$ and thus neglected. Interactions are low on zones 1 , 3 , and 4 for $f=0$ and become nil with increasing friction. Crack 1 is situated approximately in the middle of $\mathrm{ID}_{2}$, which is of the order of magnitude of crack length. $\mathrm{IF}_{2 \max }$ of -30 percent is reached in case of frictionless $140 \mu \mathrm{m}$ long cracks.
IV.3 Mode II and Mixed Mode Loading Conditions: $\mu \neq$ 0. When one crack or both are open, interaction mechanisms are different from those presented above. The stretch tilt effect and the stretch effect are encountered. Two examples illustrate the different cases that can occur.

(a) Beneficial stretch-tilt effect: $\mu=0.3$

The stretch-tilt effect occurs when one crack is open and the second partially or completely closed. These conditions are encountered for instance for $140 \mu \mathrm{m}$ long frictional cracks, with a tangential loading corresponding to $\mu=0.3$. Crack 1 is partially open. Crack 2 is open for $d / a$ less than -0.75 in the single and multiple configurations. Curves of $\mathrm{IF}_{212}$ Fig. $\left.9(a)\right)$ and $K_{121}$ (Fig. $9(b)$ ) are plotted versus $d / a$ for various crack coefficient of friction, as this effect is dependent on interfacial slip amplitude. $K_{221}$ variations are not presented as no significant difference is noted with Fig. 6 for $\mu=0$.

Zone 1: $d / a<-0.75:$ Stretch-tilt effect: both cracks are 
unloaded as they share the load; crack 1 causes $K_{121}$ to drop (negative $\mathrm{IF}_{121}$ ) and crack 2 reduces interfacial sliding along crack 1. As shown on Fig. 9(b), an increase in f favors load transfer to crack 2 until the entire load is shifted when crack 1 slip is stopped. A maximum drop IF $_{12 \mathrm{i}}$ of 18 percent is thus obtained for $f=0$.

Zone 2: $d / a>-0.75$ : identical to $\S I V .2$ (both cracks are closed)

(b) Stretch effect and negative stretch-tilt effect: $\mu=1$

Data of §IV.3a are used again, except for the tangential load which corresponds to $\mu=1$. Crack 1 is fully open and crack 2 is open also for $d / a<0.8$ (Fig. 10a and 10b). Comments are centered on mode $\mathrm{I}$.

The ID is divided in two zones:

-Zone 1: $d / a<0.8$ : Stretch effect: the load is distributed between the two cracks and both $K_{112}$ and $K_{121}$ are reduced up to 50 percent. The maximum drops for cracks 1 and 2 are obtained respectively whe crack 2 is positioned in $d / a=$ 0.0625 (i.e., under the left edge of the loading zone) and -0.5 . Reductions up to 100 percent may be obtained for crack 1 when crack 2 prevents its opening.

- Zone 2: $d / a>0.8$ : Stretch-tilt effect: both cracks are overloaded: as crack tip 2 closes $\left(K_{121}=0.\right), K_{112}$ increases and becomes slightly larger than $K_{1 \text { refl }}(6$ percent): crack 1 opening is favored by the shear plane offered by crack 2 . Here the stretch-tilt effect is harmful. Note that crack 2 interfacial friction reduces crack 1 overload as interfacial slip is reduced.

\section{Discussion}

This study attempts to explain and quantify the consequences of multiple crack interactions on SIFs and thus on the fatigue crack growth. SIFs values obtained in that parametric study correspond to fretting loading conditions alone and can be taken as values characteristic of a single step of a complete load cycle. Values obtained are in the order of magnitude of $\Delta K_{\mathrm{th}}=2.7 \mathrm{MPa} \sqrt{\mathrm{m}}$ (in case of $R=\sigma \mathrm{min} / \sigma \max =0.67$ ).

Considerable work has been performed to understand fatigue crack growth mechanisms in mode II and in mixed mode loading (I + II). Thus experiments (Pook, 1977) define a threshold $\Delta K_{2 \text { th }}$ in mode II much the same of that defined for mode I $\left(\Delta K_{2 \text { th }}=0.8 \Delta K_{1 \text { th }}\right)$. Under mixed mode loading conditions, Paris' law is used to predict fatigue crack growth with an effective $\Delta K_{\text {leff }}$ determined by $\Delta K_{\text {leff }}=\left(\Delta K_{1}^{2}+\left(0.8 \Delta K_{2}\right)^{2}\right)^{0.5}$ (Broek, 1989).

In that study, crack interactions can cause significant increases or drops in $K_{1}$ and $K_{2}$. Furthermore, $K_{112}$ and $K_{121}$ may become bigger or smaller than $\Delta K_{\text {th }}$ which was not the case for $K_{1 \text { ref1 }}$ and $K_{1 \text { ref2 }}$ and thus cause either propagation or self arrest. Thus considering $\Delta K_{112}$ and $\Delta K_{212}$ for complete load cycles may explain significant increases or drops in time life for a multiple cracked component.

\section{Conclusion}

A theoretical model of multiple fatigue cracks situated close to a loading zone have been developed. Five interaction mechanisms which depend on distance between cracks, their relative position with respect to the loading zone, crack coefficient of friction and loading conditions are discussed: the step effect, the plug effect, the tilt effect, the stretch effect and the stretchtilt effect.

Under mode II loading conditions, the step effect is the most important. Both cracks are unloaded. Crack 1 is situated in the middle of the corresponding interaction domain which is of the same order of magnitude as the crack length. Interaction factor is about 30 percent for the case reported here.

Under mixed mode loading conditions, both stretch and stretch-tilt effects are important. The interaction domain is as large as 4 times the loading zone, with crack 1 at the center. Stretch effect causes significant reductions of SIFs in mode I for both cracks, up to 50 percent in the cases considered here. Stretch-tilt effect may cause decrease or increase in SIFs in mode I, respectively of 18 and 5 percent in the cases considered.

\section{Acknowledgments}

Part of this work was performed under CEE-Brite contract $\mathrm{N}^{\circ} \mathrm{RI}$ 1B-0249-C (Project $\mathrm{N}^{\circ}$ 2418). The authors wish to thank the European Community and the industrial partners of the programme, SNECMA and BMW-RR, for the authorization to publish these results.

\section{References}

Berthe, D., Flamand, L., Foucher, D., and Godet, M., 1980, "Micropitting in Hertzian Contacts," ASME Journal of Lubrication Technology, Vol. 102 , pp. 478-489.

Broek, D., 1989, The Practical Use of Fracture Mechanics, Dordrecht, Kluwer Academic Publishers, $521 \mathrm{pp}$.

Chivers, T. C., Gordelier, S. C., 1985, "Fretting Fatigue and Contact Conditions: A Rational Explanation of Palliative Behaviour," Mechanical Engineers, Vol. 199, pp. 325-337.

Comninou, M., 1978, "The Interface Crack in a Shear Field," ASME Journal of Applied Mechanics, Vol. 45, pp. 287-290.

Dubourg, M. C., Villechaise, B., 1989, "Unilateral Contact Analysis of a Crack with Friction," European J. Mech. Sci., Vol. 25, No. 1, pp. 41-46.

Dubourg, M. C., 1989, "Le Contact Unilatéral Avec Frottement le Long de Fissures de Fatigue Dans les Liaisons Mécaniques," Thése, Doctorat, Institut National des Sciences Appliquées de Lyon et Université Lyon I, 253 pp.

Dubourg, M. C., and Villechaise, B., 1991, "Analysis of Multiple Fatigue Cracks. Part I: Theory," To be published in Journal of TruBology.

Forsyth, P. J. E., 1981, “Occurrence of Fretting Fatigue Failures in Practice." Fretting Fatigue, Ed. by R. B. Waterhouse, London, Applied Science Publishers, Ltd., pp. 99-141.

Endo, K., 1981, "Practical Observations of Initiation and Propagation of Fretting Fatigue Cracks," Fretting Fatigue, ed. by R. B. Waterhouse, London, Applied Science Publishers, Ltd. pp. 127-141.

Hills, D. A., and Comninou, M., 1985a "A Normally Loaded Half-Plane with an Edge Crack," Int. J. of Solids Structures, Vol. 21, No. 4, pp. 339-410.

Hills, D. A., Comninou, M., 1985b, "An Analysis of Fretting Fatigue Cracks During Loading Phase," Int. J. of Solids Structures, Vol. 21, No. 7, pp. 721730.

Kalker, J. J., 1990, Three-dimensional Elastic Bodies in Rolling Contact, Dordrecht, Kluwer Academic Publishers, $314 \mathrm{pp}$.

Lemaitre, J., and Chaboche, J. L., 1985, "Mécanique des Matériaux Solides," Ed. by Bordas, Paris, 532 pp.

Pook, L. P., 1977, "An Observation on Mode II Fatigue Crack Growth Threshold Behaviour," Int. Jnl. of Fracture, Vol. 13, No. 6, pp. 867-869.

Smith, J. O., and Liu, C. K., 1953, "Stresses Due to Tangential and Normal Loads on an Elastic Solid with Application to Some Contact Stress Problems," ASME Journal of Applied Mechanics, Vol. 21, pp. 157-166.

Zhou, Z. R., Fayeulle, S., and Vincent, L., "Fretting of Aluminium Alloys, Ecole Centrale de Lyon, Private Communication. 